\title{
Proteus Syndrome: A Rare Case in An Adult Ward
}

\author{
Catarina Duarte Santos, Rita Lizardo Grácio, Tatiana Costa Pires, Miguel Gonzalez Santos, \\ Rita J Rodrigues, Miriam Magalhães, Alcina Mota Ponte \\ Department of Internal Medicine, Centro Hospitalar de Leiria, Leiria, Portugal
}

Received: 09/04/2021

Accepted: $13 / 04 / 2021$

Published: 28/04/2021

How to cite this article: Duarte Santos C, Lizardo Grácio R, Costa Pires T, Gonzalez Santos M, Rodrigues RJ, Magalhães M, Mota Ponte A. Proteus syndrome: a rare case in an adult ward. EJCRIM 2021;8: doi:10.12890/2021_002554.

Conflicts of Interests: All authors declare no competing interests.

This article is licensed under a Commons Attribution Non-Commercial 4.0 License

\section{ABSTRACT}

Proteus syndrome is an extremely rare disorder that manifests as an asymmetric, disproportionate overgrowth of any connective tissue, such as bone, fat or epidermal nevi, in a mosaic or patchy pattern. It has an estimated prevalence of less than 1/1,000,000 live births. The diagnosis can be difficult because the phenotypes of the patients are variable. Many individuals develop cutaneous capillary malformation and prominent varicosities (large and complex vascular malformations). Thus, Proteus syndrome patients are at risk of developing deep vein thrombosis and pulmonary embolism. The authors present the case of a patient with Proteus syndrome who was admitted because of pulmonary thromboembolism and presented hypertrophy of the left arm and left hemithorax.

\section{LEARNING POINTS}

- Proteus syndrome is an extremely rare disorder that manifests as an asymmetric, disproportionate overgrowth of any connective tissue.

- The diagnosis can be difficult because the phenotypes are variable.

- It is important to keep in mind the importance of anticoagulation because patients are at risk of developing deep vein thrombosis and pulmonary embolism.

\section{KEYWORDS}

Proteus syndrome, overgrowth, thromboembolism

\section{INTRODUCTION}

Proteus syndrome is a very rare hamartomatous syndrome first described by the German paediatrician Rudolf Wiedermann in 1983, and was named after the Greek sea god Proteus who could change his shape to evade capture ${ }^{[1]}$. With only 250 cases reported in the literature, it has an estimated prevalence of less than $1 / 1,000,000$ live births ${ }^{[1-3]}$. This syndrome can occur in individuals of any race and shows a male predominance, with a male to female ratio of $1.9: 1.5^{[2]}$.

\section{CASE DESCRIPTION}

We present the case of a 19-year-old man with Proteus syndrome, with gigantism of the left upper limb and hemithorax, who was hospitalized for venous thromboembolism of the left brachiocephalic trunk and internal jugular vein. The patient was admitted at the emergency department because of pain and oedema of the left upper limb.

On examination, his vital signs were stable. His entire left arm was hypertrophied and he also had a large diffuse lipoma of the left chest wall (Figs. 1 and 2). His face was elongated and he had mildly slanting eyes. 


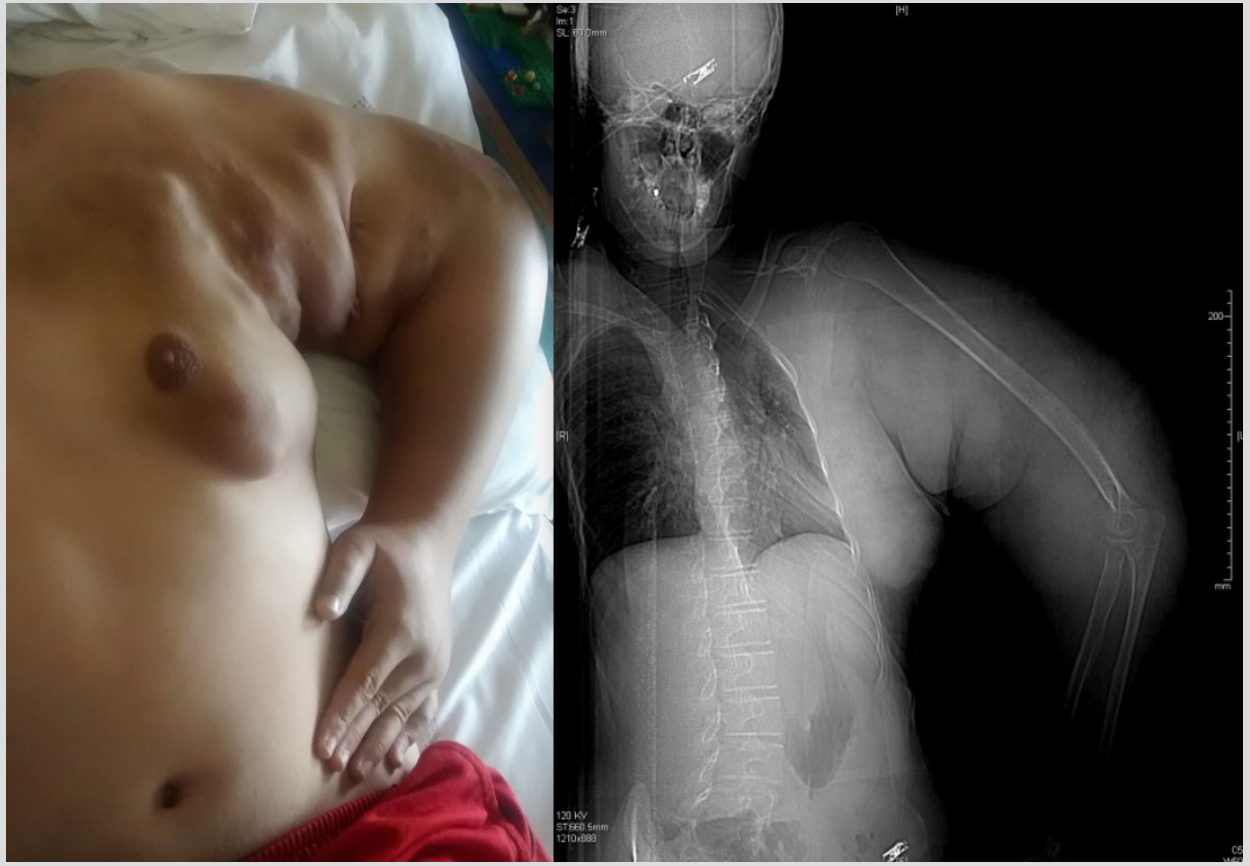

Figure 1. Gigantism of the left upper limb and lipoma of the left chest wall

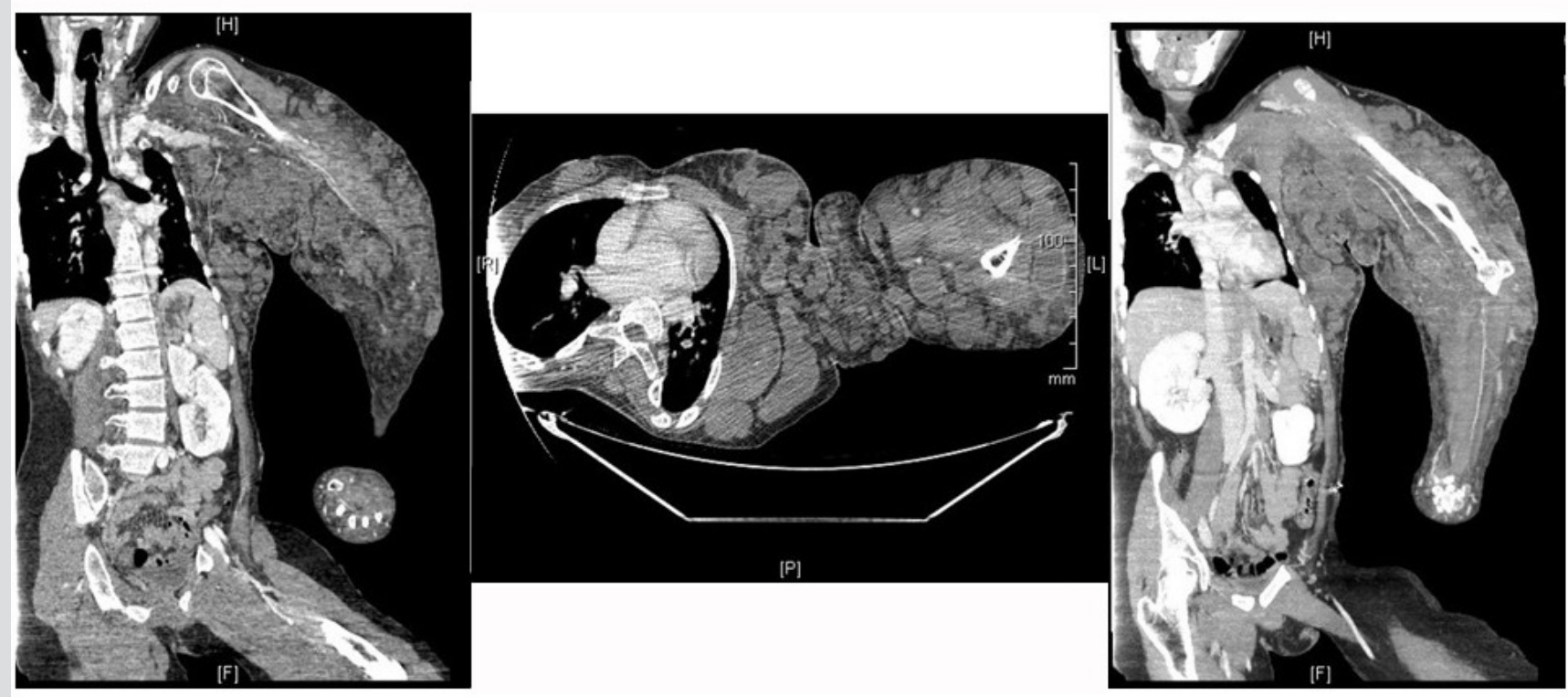

Figure 2. Excessive growth of the tissues of the left upper limb, resulting in gigantism and compression of the chest wall

Blood investigations showed leucocytosis, normocytic, normochromic anaemia (Hb $11.9 \mathrm{~g} / \mathrm{dl}$ ) and elevated D-dimers (4029 ng/ml). Doppler echocardiography of the vessels in the arm showed multiple tortuous varicose structures with phenomena of significant thrombosis; angio-CT revealed a subclavian vein slightly enlarged, with occlusion of the left brachiocephalic venous trunk and the internal jugular vein. Signs of lymphoedema were observed distally. A small deformation of the long bones was seen, with slightly irregular contours. The patient was admitted and anticoagulation with enoxaparin in therapeutic doses was started, with improvement in his condition. 


\section{DISCUSSION}

Proteus syndrome is characterized by malformations caused by excessive and multifocal growth of tissues, which results in progressive deformities including partial gigantism of the limbs, vascular malformations and organomegaly ${ }^{[4,5]}$. Most patients have normal neuropsychomotor development and a life expectancy of between 9 months and 29 years of age, depending on the severity of the abnormalities ${ }^{[6]}$. Patients usually have few or no manifestations at birth ${ }^{[1]}$. Asymmetric growth of the hands and feet starts from the age of 6-18 months and full overgrowth has occurred by age 6 . The presence of cerebriform connective tissue nevi is pathognomonic ${ }^{[7]}$, although not seen in every patient.

Many individuals develop cutaneous capillary malformation and prominent varicosities (large and complex vascular malformations). Thus, Proteus syndrome patients are at risk of developing deep vein thrombosis and pulmonary embolism ${ }^{[7]}$.

Because of the wide variability in clinical presentation, Proteus syndrome has a high rate of misdiagnosis. Therefore, specific diagnostic criteria were established in $1998^{[7]}$. Regardless of the presence of other clinical findings, diagnosis requires that the lesions have a mosaic distribution, follow a progressive course and be inherited in a sporadic fashion ${ }^{[2,7]}$. In addition to these criteria, a patient must also have: (a) a connective tissue nevus; or (b) two of the following: (i) a linear epidermal nevus; (ii) asymmetric, disproportionate overgrowth of limbs, hyperostosis of the skull, hyperostosis of the external auditory canal, megaspondylodysplasia or overgrowth of viscera (spleen or thymus); or (iii) specific tumours before the end of the second decade: ovarian cystadenoma, parotid monomorphic adenoma, testicular tumour or meningioma; or (c) all three of the following: dysregulated adipose tissue, vascular malformations, bullous pulmonary degeneration[Q4] or a specific facial phenotype ${ }^{[2,7]}$.

Identification of a mosaic, somatic, heterozygous pathogenic variant in AKT1 by molecular genetic testing can establish the diagnosis if clinical criteria are inconclusive ${ }^{[7]}$.

The most striking feature of Proteus syndrome is asymmetric disproportionate tissue overgrowth with involvement of bones and soft tissues. The overgrowth most often affects an extremity but also commonly involves the skull or vertebrae ${ }^{[2]}$.

The diagnosis is essentially clinical, and treatment is multidisciplinary and must include clinical and psychological support ${ }^{[3,4]}$. Surgical management should be directed towards functional improvement. It is important, although difficult, to manage the overgrowth in patients with Proteus syndrome. Treatment of overgrowth typically involves multiple orthopaedic procedures over years to decades. Despite aggressive treatment, patients can suffer severe functional and cosmetic consequences ${ }^{[7]}$. The psychological impact of having this syndrome raises a number of important issues: parents and affected patients commonly report feeling isolated because of the rarity of the disorder and the social stigma of having a progressively disfiguring condition. Symptoms of depression have been reported in about $23 \%$ of parents who have affected children ${ }^{[8]}$.

The main causes of death are deep vein thrombosis, pulmonary thromboembolism and respiratory failure ${ }^{[1,4,5]}$, even in young children. Thus, because of the high incidence of deep vein thrombosis and pulmonary thromboembolism, it is recommended that antithrombotic prophylaxis is considered prior to surgery ${ }^{[2,5,7]}$.

\section{CONCLUSION}

Proteus syndrome, because it is so rare, and because patients have such a short survival time, is rarely seen on adult wards. Given the frequent complications of this syndrome, we emphasize the importance of anticoagulation ad eternum in the treatment of such patients.

\section{REFERENCES}

1. Amer N, Al Helal J, Al Hajji M, Al Abduljabbar A, Al Arfaj M, Al Sadery H, et al. Proteus syndrome, a rare case with an unusual presentation: case report. Int J Surg Case Rep 2020;72:339-342.

2. Satter E. Proteus syndrome: 2 case reports and a review of the literature. Cutis 2007;80(4):297-302. PMID: 18038691.

3. Ou M, Sun Z, Zhu P, Sun G, Dai Y. Proteus syndrome: a case report and review of the literature. Mol Clin Oncol 2017;6:381-383.

4. Sene LS, de Oliveira Sales P, Chojniak R. Síndrome de Proteus: relato de caso. Rev Assoc Med Bras 2013;59(4):318-320.

5. Biesecker L. The challenges of Proteus syndrome: diagnosis and management. Eur J Hum Genet 2006;14(11):1151-1157. doi: 10.1038/sj.ejhg.5201638. PMID: 16883308.

Cruz R, Nunes ALS, Fortuna CMM, Pimentel HM, Teixeira E. Síndrome de Proteus: relato de dois casos e revisão de literatura. Rev Bras Ortop 1999;34(4).

Biesecker LG, Sapp JC. Proteus syndrome. NCBI Bookshelf, 2012. https://www.ncbi.nlm.nih.gov/books/NBK99495/

Cohen Jr MM. Proteus syndrome: an update. Am J Med Genet C Semin Med Genet 2005;137C(1):38-52. 